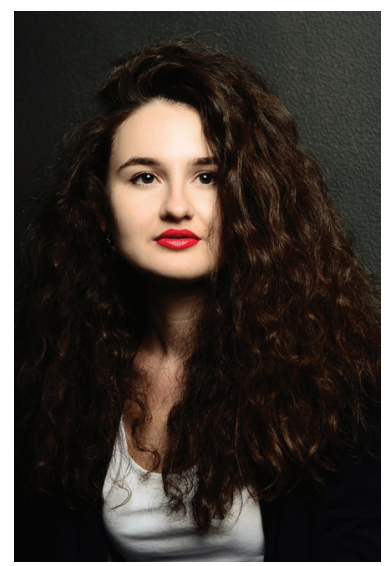

Ирина Бурган - Ukrainos P. I. Čaikovskio nacionalinès muzikos akademijos Istorijos ir kultūros teorijos katedros magistrante

Moksliniai interesai: muzikos komunikacija, kultūrinė komunikacija, muzikos kultūra

El.paštas: irinaburgan@gmail.com

Iryna Burhan - postgraduate student at the Department of Theory and History of Culture of P. I. Tchaikovsky National Music Academy of Ukraine

Research interests: communication in music, cultural communication, musical culture

E-mail: irinaburgan@gmail.com

\title{
Ирина Бурган
}

Национальная музыкальная академия Украинь имени П. И. Чайковского

\section{ЖАНР КОНЦЕРТА ДЛЯ ДВУХ ФОРТЕПИАНО С ОРКЕСТРОМ КАК ЯВЛЕНИЕ КУЛЬТУРНОЙ К ОММУНИКАЦИИ}

\begin{abstract}
Anotacija
Šiuolaikinejje kultūroje stebima stiprẻjanti tendencija - didejjantis susidomèjimas grojimu ansamblyje, todèl tampa aktualus didelès apimties ansamblio - dviejų fortepijonų koncerto - tyrimas šiuolaikinès kultūros, kaip universalios informacinès ir komunikacinès erdvès, kontekste. Kultūra yra sociokultūrinès komunikacijos priemonè, vykdoma kuriant ir perduodant komunikacinius kodus, kurie sudaro kultūros tekstą. Realizuodamas asmens kūrybinį potencialą, menas prisideda prie žmogaus kultūros suvokimo, jo įsitraukimo ị kultūros kūrimo procesą. Straipsnis skirtas dviejų fortepijonų su orkestru koncerto specifikos analizei komunikacinių kultūros procesų suvokimo kontekste.

PAGRINDINIAI ŽODŽIAI: koncertas dviem fortepijonams su orkestru, komunikacija, kultūra, kodas, koncertas, ansamblis.
\end{abstract}

\begin{abstract}
Interest in ensemble performing is increasing in modern culture, so the study of the double piano concerto, a large ensemble genre, in the context of the modern understanding of culture as a universal informational and communicative space, is relevant. Culture is a means of socio-cultural communication, carried out through the generation and transmission of communicative codes that make up the text of culture. Through the realisation of a person's creative potential in culture, art contributes to the comprehension of man's being-in-culture, and his involvement in the culturalcreative process. This article is devoted to an analysis of the specificity of the concerto for two pianos and orchestra, in the context of the theoretical understanding of communicative processes in culture.

KEY WORDS: concerto for two pianos and orchestra, communication, culture creation, code, concerto, ensemble.
\end{abstract}


В музыкальной культуре современности наблюдаются определенные тенденции актуализации ансамблевого исполнительства. Усиление интереса к ансамблевой игре характерно и для фортепианного искусства. Об этом свидетельствует ряд факторов. Во-первых, создание известными профессиональными музыкантами коллабораций для исполнения ансамблевого репертуара. Подобное сотворчество, как правило, носит временный характер, но производит фурор, как среди поклонников конкретных артистов, так и в широком кругу ценителей классической музыки. Известные исполнители объединяются в новую творческую единицу, «звездный тандем», от которого всегда ждут создания высокопрофессионального музыкального продукта (исполнения), оригинальности в подходе к выбору репертуара и его интерпретации. Появление нового «музыкального созвездия» - всегда событие в музыкальной и околомузыкальной сферах. Иногда плодотворная совместная работа музыкантов трансформируется в настоящую творческую дружбу, которая длится годами или даже десятилетиями. Подобные творческие тандемы известны не только успешными концертами, но и наличием великолепных записей, подчеркивающих большую художественную ценность результатов сотрудничества.

Отметим, что для современного музыкального исполнительства характерен рост популярности такого явления, как постоянно функционирующие ансамбли. Все большее количество музыкантов выбирают путь «узкой» специализации, фокусируя свое творческое внимание исключительно на игре в ансамбле, строя свою музыкальную карьеру в рамках конкретного проекта, который впоследствии становится самостоятельной, узнаваемой творческой единицей.

Пути развития европейского и общемирового музыкально-культурного процесса в наше время актуализируются в конкурсах и фестивалях. С одной стороны, в конкурсно-фестивальних программах отражены острейшие, актуальнейшие потребности современного музыканта. С другой стороны, эта специфическая индустрия сама способна «задавать тон», диктовать профессиональные и репертуарные требования слушателям и исполнителям. Тем не менее, значимость конкурсов и фестивалей для современной культуры трудно переоценить. Украинский музыковед М. Пухлянко называет музыкальные конкурсы «универсальными коммуникационными каналами, способными устанавливать, поддерживать и стимулировать реальные общественные и художественно-творческие взаимосвязи» (Пухлянко 2012, 42).

Актуализация ансамблевого исполнительства проявляется в таких формах продукции современной музыкальной индустрии, как концерт и аудио / видеозапись. В концертные программы филармоний и прочих 
концертных организаций все чаще включаются ансамблевые и ансамблево-симфонические проекты. Музыканты работают над созданием альбомов ансамблевой музыки, в которых присутствуют как популярные композиции, так и малоизвестные, а также совсем новые произведения. Это свидетельствует, во-первых, о стремлении «открыть» миру уникальность, оригинальность ансамблевой культуры. А во-вторых, об активном поиске исполнителями нового репертуара, что, следовательно, порождает ответную активизацию композиторского творчества.

Усиление общего интереса к ансамблевой музыке среди исполнителей способствовало возникновению научного интереса к ансамблевым жанрам и специфике ансамблевого музицирования. Труды по истории, психологии, методике и педагогике ансамблевого исполнительства активно пополняют теоретическую базу исследований ансамблевого мастерства. А изучение истории и разработка теории ансамблевых жанров способствует научному осмыслению результатов композиторской активности в музыкально-культурном контексте. С учетом вышесказанного особенно актуальным становится исследование жанра, органично сочетающего в себе различные проявления инструментальной ансамблевости: фортепианную ансамблевость - с ансамблевостью симфонической. Концерт для двух фортепиано с оркестром - жанр, который продолжает переживать период своего ренессанса и актуализации в музыкальной культуре. Специфика его ансамблевого устройства характеризуется усилением коммуникативного процесса. А это предоставляет возможность особого подхода к его исследованию с позиции современного видения культуры - как универсального информационно-коммуникативного пространства. Целью исследования является анализ специфики концерта для двух фортепиано с оркестром в контексте теоретического осмысления коммуникативных процессов в культуре.

По данным исследования Е. Береговой в мировом концептуальном пространстве насчитывается более 160 определений понятия коммуникации, а история самого слова communicato (лат. - делать общим, связывать; общаться) насчитывает минимум две тысячи лет (Берегова 2009, 20, 13). Несмотря на то, что первая коммуникативная модель была теоретически сформулирована во времена Древней Греции (автором концепта исследователи считают Аристотеля), теория коммуникации становится самостоятельной отраслью научного знания и получает колоссальное развитие только в XX веке, и считается довольно молодым направлением в науке. Ее становление связано с появлением таких дисциплин, как информатика, семиотика, кибернетика. Известно, что потребность в изучении коммуникации возникла в связи с активной разработкой и введением в эксплуата- 
цию технических средств передачи информации. Таким образом, в XX веке коммуникация обрела статус самостоятельного объекта научного исследования. Очевидный «подъем» коммуникативного процесса, актуальный для прошлого столетия, сегодня продолжает набирать обороты. В ситуации массового распространения Интернета и совершенствования инновационных технических средств связи общество XXI века переживает небывалый масштаб коммуникации. Релевантная методология изучения коммуникации и коммуникативных процессов предусматривает кросс-дисциплинарный подход. Различные аспекты коммуникации исследуются в комплексах социогуманитарных, естественных и технических наук. Современная трактовка понятия «коммуникация» в общекультурном контексте предполагает несколько вариантов понимания. В качестве примера приведем классификацию Е. Береговой: «1) передача чего-то в пространстве, пути сообщения (железнодорожные, водные (...)), а также сети подземного хозяйства (подземные коммуникации (...)); 2) формы связи - сигнальной, электромагнитной, световой, звуковой или средства - речи, письма (..); 3) межличностное общение, основанное на стремлении к взаимопониманию или на простом взаимоинформировании; 4) массовая коммуникация как процесс обмена информацией путем использования общедоступных технических средств массовой информации» (Берегова 2009, 19). Данная классификация достаточно подробно раскрывает многоаспектность изучаемого понятия. В свою очередь мы можем сделать и более общие выводы. Во-первых, коммуникация предполагает наличие некой связи между ее субъектами. Во-вторых, служит передаче (обмену) материальных объектов либо сигналов в физическом пространстве. И, в-третьих, она нацелена на достижение определенного результата коммуникации.

Так как исследование коммуникации в значении обмена физическими объектами в пространстве не является целью нашей работы, рассмотрим те аспекты этого понятия, которые представляются наиболее близкими нашей теме. К таким относится межличностное, социальное взаимодействие. Ведь известно, что культура является продуктом человеческой активности, создается и реализуется человеком как социальным элементом. Существование Другого, носителя иной культуры - национальной либо индивидуальной необходимо для максимально полного отражения в культурной реальности явлений действительного мира. В интеракции с Другим возможна и генерация новейшего в культуре, ее обогащение, культуротворчество. Поэтому стоит прояснить механизм коммуникативного взаимодействия в обществе.

Социальная коммуникация представляет собой определенную систему, которая состоит из последовательности «взаимосвязанных социально 
значимых коммуникативных актов, таких как вхождение в коммуникативный континуум (коммуникативную ситуацию), индивидуально-личностная и социально-значимая оценка ситуации, выбор субъекта для возможного взаимодействия, постановка цели и задачи коммуникативного диалогического взаимодействия и формирования коммуникативного дискурса» (Куликов 2010, 11). Эволюция методологии исследования социальной коммуникации в исторической ретроспективе ее теоретического осмысления представлена несколькими вариантами научных подходов. Парадигма, основывающаяся на классической позитивистской методологии, предусматривала диспозицию субъект-объект. Подобный вариант презентуется концепцией структурного функционализма, базируется на системном методе, концептах информационного общества и технологического детерминизма. Неклассический подход базировался на когнитивной модели субъектнообъектных отношений. В феноменологической парадигме сфера коммуникации рассматривалась как специфический онтологический объект, в научном осмыслении коммуникативной (интерактивной) сферы использовались методы герменевтической интерпретации смыслов, критической рефлексии, рациональной реконструкции. Постнеклассическая методологическая модель базируется на интерсубъектном подходе к явлению коммуникации, отрицая объектность в социальном (Куликов 2010, 16-17).

Культура является частью социального пространства, она не может существовать без человека. Поэтому есть смысл говорить о социокультурном пространстве и, следовательно, о социокультурной коммуникации - взаимодействии людей в поле культуры. Социокультурная коммуникация реализует переход коммуникативного вектора в конкретный результат взаимодействия субъектов интеракции. Механизм коммуникации осуществляется следующим образом: наличие предпосылок к взаимодействию, их интенсификация и переход в потребность в коммуникации, затем поиск соответствующего канала и формы передачи информации, непосредственно информирование либо взаимоинформирование субъектов и, наконец, достижение прогнозируемого результата коммуникативного взаимодействия. Информация не является объектом материального мира, однако обмен ею происходит в физическом пространстве. Следовательно, в ходе ее передачи используется подмена реального абстрактным, некий шифр, символ. Исследователь Г. Почепцов трактовал сущность коммуникации как процесс обмена сигналами, при котором осуществляется «перекодировка вербальной в невербальную и невербальной в вербальную сферы» (Почепцов 2001, 15). В ходе обмена сигналами «низкого уровня энергии (организации)» осуществляется переход к обмену сигналами «высокого уровня энергии (ор- 
ганизации)», как к определенному результату трансформации. Благодаря тому, что между любым минимальным сигналом системы и сигналом-максимумом существует связь, при обмене минимумом, появляется возможность достичь максимума (Почепцов 2001, 15). Подобная система представляет собой код. А это значит, что в ней каждая деталь содержательного плана отражена соответствующим образом в выразительном плане. Кодовая система нацелена на осуществление обмена нефизическим в физическом пространстве.

Культура обладает способностью генерировать коммуникативные коды. Кроме того, необходимым условием существования культуры является наличие Другого - другой культуры, другого кода. Культура не может быть построена на одном коде. Этот факт не имеет негативного подтекста, а напротив, представляется необходимым условием существования культуры. Иллюзорную модель единого унифицированного коммуникативного кода стоит заменить представлением о коммуникативной структуре минимум из двух (и более) принципиально разных, взаимно необходимых друг другу кодов. Итак, культура «заинтересована» в множественности кодов. Ситуация множественности является естественной, первичной, однако, культура тяготеет к универсализации, состояния «единой истины». Последнее возможно для «вторичной» реальности, генерируемой культурой. Поэтому интеракция множественного и единичного относится к основным фундаментальным признакам культуры (Лотман 1992, 9-10). Культура в целом является в некотором смысле текстом. Обратим внимание на сложность устройства такого текста, его иерархическое разделение на «тексты в текстах», сложные сплетения тестов. Опираясь на этимологию слова «текст» в значении «сплетение», понятию «текст» таким образом возвращается его первоначальное смысловое наполнение (Лотман 1992, 121-122). На основе семиотического подхода Е. Береговая делает следующий вывод: «Поскольку с культурно-семантической точки зрения любой культурный объект или процесс обладает символическими свойствами и в силу этого является культурным текстом, то это значит, что средством социокультурной коммуникации является вся культура как системная совокупность различных культурных феноменов и процессов, а также каждый ее феномен и процесс, взятый отдельно. Непосредственным носителем информации об атрибутивных признаках того или иного культурного текста, его функциональной нагрузке, структурно-иерархическом статусе в системе и т. д. выступает культурная форма соответствующего объекта, явления или процесса» (Берегова 2009, 24). 
Ж. Делёз писал: «У нас нет недостатка в коммуникации - наоборот, у нас ее даже в избытке, но нам недостает творчества» (Делёз 1998, 141). Творчество человека в культуре (культуротворчество) проявляется как в генерации новых объектов культуры, культурных форм и смыслов, так и в интерпретации уже имеющихся, их оценке. В обоих случаях будет задействован творческий потенциал личности, которая таким образом постигает свое Я, свой духовный микрокосм, познавая его через макрокосм культуры. В конечном итоге человек, путем объективации творческой силы, познает сущность (и единство) социального и индивидуального аспектов своего бытия через бытие-в-культуре. Сфера искусства является результатом деятельности человеческого сознания на высочайшем уровне. Искусство побуждает человека к реализации творческого потенциала, запуская процессы осознания человеком своей причастности к культуре и культуротворческому процессу, принятия своего бытия-в-культуре. Как составляющая культуры, искусство генерирует определенные коммуникативные коды, что позволяет говорить о возможности культуротворческой коммуникации, которая осуществляется средствами искусства и с помощью общения в контексте творчества.

Музыкальное искусство (и, в частности, фортепианное) основывается на принципе, который был заложен Аристотелем. В современной интерпретации он известен как «оратор - речь - аудитория». В виду того, что люди не имеют возможности общаться напрямую, с помощью телекинеза, музыку можно считать языком - одним из кодов культуры. Музыкант в концертной ситуации предстает в роли оратора, его эмоциональный посыл через музыку побуждает слушателя к общему переживанию, проекции ощущений оратора на себя, благодаря чему оратор ассоциируется с Я, ощущается как Я. Это позволяет слушателю увидеть свои чувства со стороны, при этом переживая и со-переживая.

Жанр концерта для двух фортепиано с оркестром способствует усложнению классической коммуникативной структуры. Наличие солирующего фортепианного ансамбля «на первом плане» и оркестрового сопровождения видоизменяет известную схему в нескольких направлениях. Во-первых, коммуникативный компонент «оратор» дублируется. Пара солистов с помощью музыкальных средств и наглядности образа воплощает две грани акта самосознания - «Я» и «Другого». С одной стороны, наличие «двух» подчеркивает важность «одного» - индивидуальности, личности (которая является «почвой» для интеракции), ее ценности для «другого» (партнера) и «других» (оркестра). С другой стороны, на первом плане презентуется момент встречи, когда «Я» встречает «Ты», акцентируется момент «отношения», в котором оба субъекта по-настоящему раскрываются. В рамках 
относительно унифицированного кода фортепианной музыки символически воспроизводится необходимость «двух», которые являются носителями различных индивидуальных культур, но их взаимодействие делает культурный мир более полным, более настоящим. Роль оркестра в коммуникативном процессе также многоплановая. В схеме «оратор - речь - аудитория» при наличии двух солистов-ораторов оркестру должна была отойти роль «лица, к которому обращаются» (по Аристотелю) (Аристотель 2000, 14). Но к оркестру не только «обращаются», он также «отвечает». Оркестр ассоциируется с «активным большинством», не воспринимается как «большинство - объект воздействия». (Видимо, не зря жанр концерта называют демократичным. Такую его направленность воспроизводят не только яркие, «плакатные» средства выразительности, но и роль оркестра.) При наличии двух солистов - коммуникативной связи Я-Другой - оркестр также выполняет функции «третьего лица». Его можно сравнить со словами автора в литературе. Музыкальный текст двойного концерта, как разновидность художественного текста, сохраняет свою направленность на «усложнение отношений между первым и третьим лицом, то есть между тяготением к пространству имен и объективным повествованием от третьего лица» (Лотман 1992, 60). Таким образом, оркестр комбинирует роли участника коммуникации и комментатора. Это создает в двойном концерте ситуацию «текста в тексте». Иерархия текстов также подкрепляется множественностью коммуникативных кодов, которые генерировались в культуре сольного фортепианного, оркестрово-симфонического и ансамблевого исполнительства, но в данный момент взаимодействуют в концерте для двух фортепиано с оркестром. В двойном концерте реализуется один из ключевых семиотических механизмов человека «возможность быть «только собой», вещью (собственным именем) и одновременно выступать в качестве «представителя» группы, одного из многих (нарицательное имя)» (Лотман 1992, 58). Этот механизм прослеживается на всех уровнях сценического взаимодействия в концерте: между солистами, в оркестре, на общем уровне совместного исполнения произведения.

Этимология термина «концерт» предполагает двойную интерпретацию смыслов касательно сущности этого жанра: с одной стороны «соревнование», с другой «согласие». Несомненно, в концертном жанре присутствуют оба начала. В концерте для двух фортепиано с оркестром, в отличие от концерта для одного фортепиано, диалектика «агоническое-гармоничное» осуществляется на нескольких уровнях. Это не только «единичное-множественное» (солист-оркестр), носящее более абстрактный характер, так как, обращаясь ко многим, мы не обращаемся ни к кому конкретно. Добавля- 
ется еще один план более персонифицированный, личностный. Это «соперничество-согласие» в рамках солирующего ансамбля. Межличностная коммуникация происходит на авансцене, подается как бы крупным планом, в первую очередь приковывает внимание слушателя. Диалог в таком контексте создает момент особой акцентуации на коммуникации как культуротворческом акте. Вторым планом уже воспринимается интеракция солистов с оркестром. Традиционно это подчеркивается «монохромностью» звучания фортепиано и разнообразием тембров оркестра.

Агоническое начало в концерте делает этот жанр важнейшим для современного исполнителя. В наше время культурный мир переживает настоящий конкурсный «бум». Художественная культура развивается путем агона, соревнования. Не становится исключением и музыкальная культура. Участие и лауреатство в престижных международных музыкальных соревнованиях становятся практически неотъемлемым пунктом в резюме известных исполнителей. Яркое агоническое начало в концерте, его масштабность и сложность в исполнении делает эту жанровую категорию обязательной репертуарной составляющей многих музыкальных конкурсов. В частности, как нельзя лучше концерт подходит для финального тура, поэтому именно от исполнения концерта зависит судьба лучших участников соревнования будущих победителей. В связи с общим ростом конкурсного движения и усилением интереса к ансамблевому исполнительству возникают и становятся популярными конкурсы фортепианного ансамблевого и дуэтного исполнительства. Чем большего масштаба и популярности достигали ансамблевые соревнования, тем более вероятным было ожидаемое появление ансамблево-симфонического финального тура и в таких конкурсах. Среди престижных международных конкурсов фортепианно-ансамблевого исполнительства назовем Murray Dranoff Two Piano Competition (США, Майами, Флорида), ARD International Music Competition (Мюнхен, Германия), International Piano Duo Competition in Bialystok (Польша). Самыми популярными концертами согласно конкурсным репертуарным требованиям на сегодняшний день являются Концерт и для двух фортепиано с оркестром ми бемоль мажор KV365 В. А. Моцарта и ре минор FP 61 Ф. Пуленка.

Начав путь своего ренессанса в культурном пространстве XX века с концертных программ, с появлением современных музыкальных конкурсов, подготовка к которым требует от исполнителей активизации концертной практики для «обыгрывания» программы, концерт для двух фортепиано с оркестром значительно укрепил свои позиции на концертной эстраде. По сравнению с концертами для одного фортепиано, двойные концерты не на столько востребованы, потому что большинство пианистов нацелены все же 
на сольную карьеру, сольную деятельность. Возникают также сложности с выбором партнера, наличием в зале двух качественных инструментов, наличием сцены достаточно большого размер для размещения двух концертных роялей и симфонического оркестра. Естественно, существует ряд факторов, которые делают двойной концерт не очень универсальным жанром. Однако он влечет исполнителей и публику своей экзотичностью, необычностью, масштабностью, что также представляет интерес для современной музыкальной индустрии, в которой важным компонентом стал момент эпатажа слушателя.

Итак, культура является средством социокультурной коммуникации, реализуемой через генерирование и трансляцию коммуникативных кодов, составляющих культурный текст. Искусство путем реализации творческого потенциала человека в культуре способствует постижению человеком своего бытия-в-культуре, своей причастности к культуротворческому процессу. Наличие в культурном пространстве коммуникативных кодов из сферы искусства предопределяет возможность культуротворческой коммуникации, а музыка выступает одним из «языков» культуры. Жанр концерта для двух фортепиано с оркестром, по отношению к фортепианному искусству в целом, усложняет классическую коммуникативную схему «оратор - речь аудитория». Персонификация диалога на уровне отношения «Я-Ты» в контексте интеракции «Я-Другой» и «Я-Другие» создает в двойном концерте момент особой акцентуации на межличностной коммуникации как культуротворческом акте.

\section{Литература}

Аристотель 2000 - Аристотель. Риторика. Пер. с древнегреческого и примеч. О. П. Цыпенко, под ред. О. А. Сычева и И. В. Пешкова. Москва: Лабиринт. 224 с.

Берегова 2009 - О. М. Берегова. Культура та комунікація: дискурси культуротворення в Україні в ХХІ столітті. Київ: Інститут культурології АМУ. 184 с.

Делёз 1998 - Ж. Делёз, Ф. Гваттари. Что такое философия? Пер. с фр. и послесл. С. Н. Зенкина. Санкт-Петербург: Алетейя. 288 с.

Куликов 2010 - С. В. Куликов. Социальная коммуникация: дискурсивно-диалогическая природа и характерологические особенности: автореф. дис. канд. философских наук: спец. 09.00.11 Социальная философия. Ростов-на-Дону. 28 с.

Лотман 1992 - Ю. М. Лотман. Культура и взрыьв. Москва: Гнозис. 272 с.

Почепцов 2001 - Г. Г. Почепцов. Теория коммуникации. Москва: Рефл-бук. 656 с.

Пухлянко 2012 - М. Є. Пухлянко. Передумови формування сучасного конкурсу музикантіввиконавців: до поняття «змагальності» в історії культури. Київське музикознавство. Культурологія та мистецтвознавство : зб. ст. Київський ін-т музики ім. Р. М. Глієра. Вип. 41. Київ, 42-49. 


\section{Iryna Burgan}

\section{THE GENRE OF THE CONCERTO FOR TWO PIANOS AND ORCHESTRA AS A PHENOMENON OF CULTURAL COMMUNICATION}

Summary

Interest in ensemble art is increasing in modern culture. Therefore, it is relevant to study the genre, which combines organically various manifestations of the instrumental ensemble: the piano ensemble and the symphonic ensemble. The concerto for two pianos and orchestra is a genre that is continuing its renaissance and actualisation in musical culture. The specificity of its ensemble structure is characterised by the increased communication process. This provides an opportunity for a special approach to its study from the position of the modern vision of culture as a universal informative and communicative space.

The article is devoted to an analysis of the specifics of the concerto for two pianos and orchestra, in the context of the theoretical understanding of communicative processes in culture. Culture is a means of socio-cultural communication, carried out through the generation and transmission of communicative codes that make up the text of culture. Through the realisation of a person's creative potential in culture, art contributes to the comprehension of man's being-in-culture, and his involvement in the cultural-creative process. The presence of communicative codes in the field of culture and art predetermines the possibility for cultural communication, and music is one of the 'languages' of culture. The genre of the concerto for two pianos and orchestra in the context of piano art contributes to the complication of the Classical communicative scheme 'speaker-speech-audience'. The personification of the dialogue at the 'I-Thou' relationship level in the context of 'I-Other' and 'I-Others' interactions in the double concerto focuses on interpersonal communication as a cultural-creative act. 